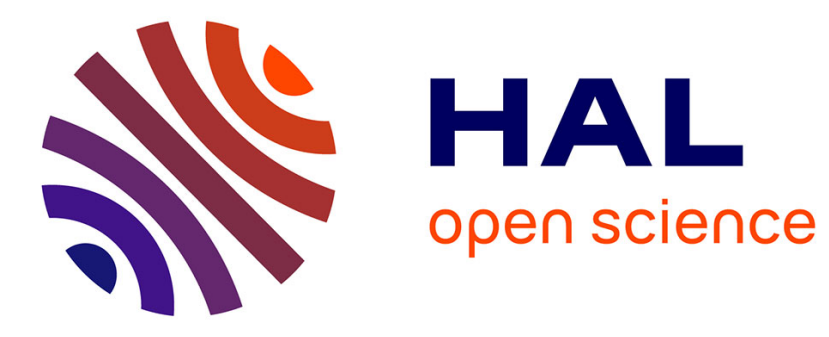

\title{
Experimental temperature compensation on drop-on-demand Inkjet printing
}

Ludivine Fadel, Stéphanie Poirier, Sylvie Vinsonneau, Fabien Mesnilgrente, Pierre Temple-Boyer

\section{- To cite this version:}

Ludivine Fadel, Stéphanie Poirier, Sylvie Vinsonneau, Fabien Mesnilgrente, Pierre Temple-Boyer. Experimental temperature compensation on drop-on-demand Inkjet printing. Micro and Nanosystems, 2010, 2 (2), pp.137-141. hal-00827605

\section{HAL Id: hal-00827605 https://hal.science/hal-00827605}

Submitted on 31 May 2013

HAL is a multi-disciplinary open access archive for the deposit and dissemination of scientific research documents, whether they are published or not. The documents may come from teaching and research institutions in France or abroad, or from public or private research centers.
L'archive ouverte pluridisciplinaire HAL, est destinée au dépôt et à la diffusion de documents scientifiques de niveau recherche, publiés ou non, émanant des établissements d'enseignement et de recherche français ou étrangers, des laboratoires publics ou privés. 


\title{
Experimental Temperature Compensation on Drop-On-Demand Inkjet Printing
}

\author{
Ludivine Fadel Taris $^{* 1,2}$, Stéphanie Poirier ${ }^{1,2}$, Sylvie Vinsonneau ${ }^{3}$, Fabien Mesnilgrente ${ }^{1,2}$, Pierre Temple- \\ Boyer $^{1,2}$ \\ 1 CNRS; LAAS ; 7 avenue du colonel Roche, F-31077 Toulouse, France \\ 2 Université de Toulouse; UPS, INSA, INP, ISAE ; LAAS, F-31077 Toulouse, France \\ 3 ESSILOR International, Toulouse, France
}

\begin{abstract}
The paper demonstrates the interest in using temperature compensation to stabilize drop-on-demand inkjet printing process. The influence of inkjet printing parameters on the droplet velocity and ejection stability is particularly discussed. Based on experimental results a relation between the printing parameters and kinetic property of drops is drawn. Adjusting the amplitude pulse applied to the dispenser head, the drop velocity is stable over a $15^{\circ} \mathrm{C}$ variation, where as it increases by $5 \mathrm{~m} / \mathrm{s}$ without compensation and the print quality is so optimized.
\end{abstract}

Keywords: Droplets characteristics, Drop-on-demand inkjet printing, Temperature compensation.

\section{INTRODUCTION}

Inkjet printing developed in the seventies was first dedicated to office printers and industry of graphic applications. Nowadays its use has been extended to various applications such as sensors, MEMS [1,2], medical diagnostic [3], organic electronics (RFID, TFTs), or displays $[4,5]$. This technology is a non impact dot matrix printing technology in which droplets of ink are directly jetted from a small aperture to a specified position on a media. There are two methods of inkjet printing with various dedicated solutions [6]. The first discovered inkjet printing method was continuous inkjet whereby a continuous ink stream is broken into droplets of uniform size and spacing [7]. The second method is drop-on-demand technology allowing the printhead to generate ink drops on request. On the application of voltage pulses, ink drops are ejected by a pressure wave created by mechanical motions of piezoelectric ceramic actuators. The main interests in this technique are both the quality of print and the good accuracy of layers positioning. Current research activities focus on the dynamical mechanisms of drop formation and fluid rupture from a nozzle under the influence of gravity alone (i.e. dripping regime) or due to the application of external forces (i.e. jetting regime) $[8,9]$. A low speed of ejection makes the drops disrupted by the air fluctuations. For high speed ejection, a breakup of the free liquid thread leads to the generation of a primary drop and satellites. In both case the drop position is not accurate.An important issue is the control of the ejected drops properties (volume and velocity). These properties depend on the rheology of the liquid (viscosity, density, tension of surface) and the features of the electrical signal (frequency, pulse amplitude and impulsion width) applied to the print head. The most contributing parameter is the viscosity which is thermal dependent. In the manifold of ink it is usually regulated by an external system. Within the piezoelectric actuator, the heating phenomenon induced by high frequency printing ejection $(1-10 \mathrm{kHz})$ is seldom balanced. As a matter of consequence the liquid viscosity lessens thus modulating the drop characteristics. To overcome this drift and accurately deposit small volumes of liquid material over a long period of time, a compensation of thermal variations is required.One solution proposed by Zapka et.al is to use the capacitance of the channel walls as a temperature sensor [10]. It is based on the fluctuation of dielectric permittivity induced by temperature changes. The measurement of inert-wall capacitance was performed on a print head whose the cover material has been changed from PZT to aluminum nitride (AlN). Presenting almost the same mechanical characteristics as PZT it provides a larger thermal conductivity which allows for a better sensitivity to the temperature variations. However this approach requires some modifications of the inkjet printer material and dedicated equipment for the capacitance measurement which are assumed to be expensive.

In this paper we propose a low cost alternative based on an experimental study of the inkjet parameters contributing to the drop velocity. The investigations first allow determining a relation between the liquid temperature and the pulse amplitude. The temperature compensation effect is then analysed and discussed.

\section{EXPERIMENTAL}

For drop-on-demand systems the most common technology is piezoelectric inkjet (used by e.g. Xaar, Epson...) which uses the inverse piezoelectric effect: ceramic materials shape is changed when a voltage is applied across it. The inkjet print heads studied in this work are Xaar760® shear mode inkjet actuator, series "greyscale", where the dispenser head eject drops of variable volume. These are formed by producing pools of sub-droplets at high frequency. The number of droplets per group depends on the print head specifications (number of greyscale levels) [11].

In such a case of study they are featured with $27 \mu \mathrm{m}$ nozzle aperture, and the deformation of piezoelectric actuators is used to create an ink volume 
change in the pressure chamber. The actuator is composed of a base plate made of piezoelectric lead Zirconate Titanate (PZT) ceramic, and an inactive cover plate (Fig. 1). Multiple ink channels featuring the base plate within a channel are connected galvanically at the wire bond area. The cover plate is glued onto the base plate [12].

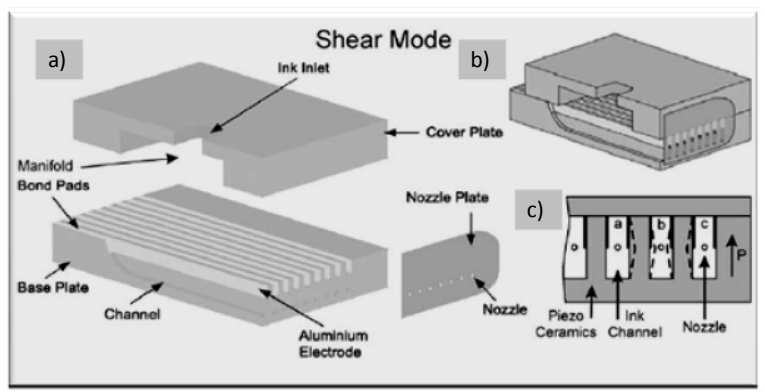

FIG.1. Configuration of a shear mode actuator, in inside section ( $a$ and $b$ ) and in cross-section (c). [12].

For drop generation, driving voltage signals are applied to the electrodes, generating orthogonal fields to the polarizing direction in the channel walls (Fig. 2). This produces shear mode motion in the upper half of the channel wall.

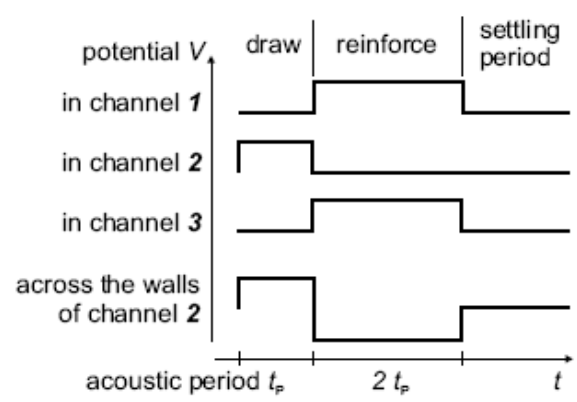

FIG.2. Typical waveforms of the driving voltage signal applied to the shear mode actuator for drop generation [12].

A negative signal pulse deforms the piezoelectric crystal which creates two acoustic waves of compression. During the positive pressure, the acoustic wave splits up and propagates in both directions. This causes a contraction of walls inside the channel which strengthens the phenomenon of overpressure within the liquid and introduces the ejection of the drop. The reflection of the acoustic wave inverts the pressure at the manifold. It creates the breakup of the ligament whereas the depression, at the opposite edge, sucks up the liquid of the manifold to fill again the channel. The liquid is silicon oil referred as DC 704 from Dow Corning. Its viscosity must be included within a 6 to $15 \mathrm{cP}$ range for a temperature below $65^{\circ} \mathrm{C}$. It is measured by a Brookfield cone/plate rheometer. The droplet formation has been observed with a stroboscopic optical system composed of a CCD camera synchronized with a strobe LED system. The whole system is automatically controlled through GPIB connections. The velocity calculation relies on the ratio between the drop distance and fall time of a spark. The experimental study consists in determining the variations of the drop velocity of Xaar760® print head under the influence of:

(i) The amplitude and impulsion width of the waveform

(ii) The viscosity of the liquid. The influence of the waveform shape is not considered here since it is not allowed with the referenced print head.

We have first tested the impact of impulsion width sent to the piezoactuator at $38.5^{\circ} \mathrm{C}$ and $46.8^{\circ} \mathrm{C}$; the pulse amplitude and frequency were fixed to $10 \mathrm{~V}$ and $2000 \mathrm{~Hz}$, respectively. The obtained results highlight an optimum impulsion width (260 ns) maximizing the drop velocity (Fig.3).

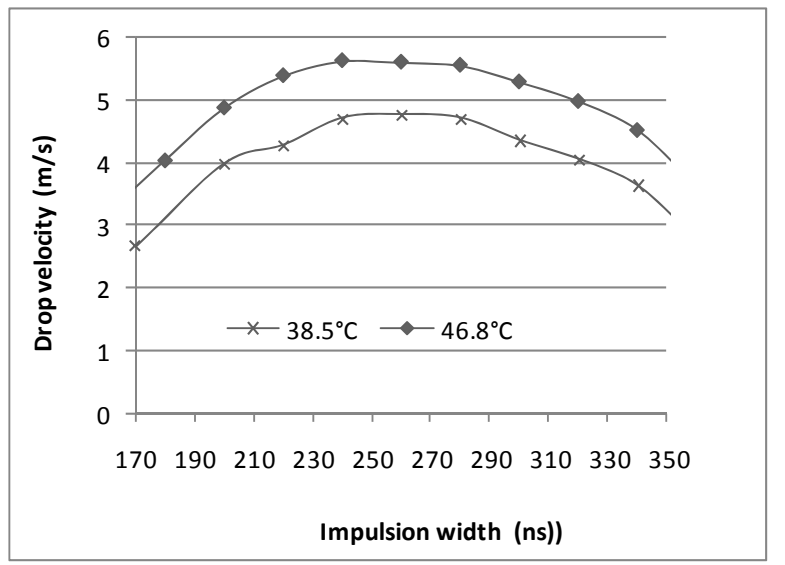

FIG.3. Drop velocity variations versus impulsion width with the Xaar760® print head.

Once the optimal value of impulsion width is fixed we investigate the effect of pulse amplitude. For the remaining part of tests, the frequency of ejection has been tuned to $1 \mathrm{kHz}$ and the binary mode (small drop size $=8 \mathrm{pl}$ ) has been selected.

\section{RESULT AND DISCUSSION}

As reported in Fig. (4), the drop velocity increases linearly with pulse amplitude. Indeed, a larger amplitude implies more motion of the piezoactuator which increases the kinetic energy transferred to drops.

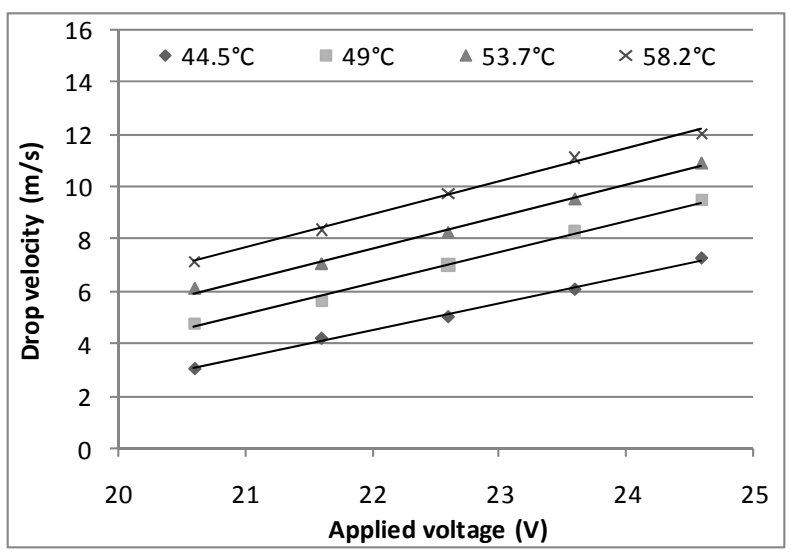

FIG.4. Pulse amplitude effect on the drop velocity of DC 704 silicon oil at different temperature. 
Furthermore, a constant slope is evidenced for all curves. So, we can assume a proportional variation of the drop velocity, to the pulse amplitude:

$\mathrm{v}=\mathrm{C}_{1} \times \mathrm{U}^{\prime}+\mathrm{C}_{1}^{\prime}$

Where $\mathrm{v}$ is drop velocity, $\mathrm{U}$ is applied voltage, $\mathrm{C}_{1}$ is a constant (curves slope are independent of temperature) and $\mathrm{C}^{\prime}{ }_{1}$ a variable depending on ejection temperature.

Experimentally the equation (1) becomes:

$\mathrm{v}=1.18 \times \mathrm{U}+\mathrm{C}_{1}^{\prime}$

$\left(\right.$ root mean square $\left.=0.09 \mathrm{~m} \cdot \mathrm{s}^{-1} \cdot \mathrm{V}^{-1}\right)$

We equally observed the influence of the temperature head on the drop velocity. Fig. (5) depicts that it increases with the temperature. Besides, the relation of dependence in temperature of the viscosity follows an Arrhenius law:

$$
\eta=\eta_{0} \mathrm{e}^{\mathrm{E} / \mathrm{kT}}
$$

Where $\eta$ is the viscosity, $\eta_{0}$ a constant, $T$ is the absolute temperature in ${ }^{\circ} \mathrm{K}, \mathrm{E}$ is the energy of activation, $\mathrm{k}$ is the Boltzmann constant.

Experimental values obtained by measuring DC 704 silicon oil viscosity with Brookfield rheometer give:

$$
\eta=4.10^{-5} \mathrm{e}^{4150 /(\theta+273.15)}
$$

Where $\theta$ is the temperature in Celsius degrees.

Using equation (4), the linear dependency of the drop velocity versus viscosity is illustrated in Fig. (6):

$$
\mathrm{v}=\mathrm{C}_{2} \times \eta+\mathrm{C}_{2}^{\prime}
$$

Where $\mathrm{C}_{2}$ is a constant (curves slope are independent of pulse amplitude) and $\mathrm{C}_{2}{ }_{2}$ a variable depending on pulse amplitude. The experimental values give:

$$
v=-0.6 \times \eta+C_{2}^{\prime}
$$

$\left(\right.$ root mean square $\left.=0.04 \mathrm{~m} \cdot \mathrm{s}^{-1} \cdot \mathrm{cP}^{-1}\right)$

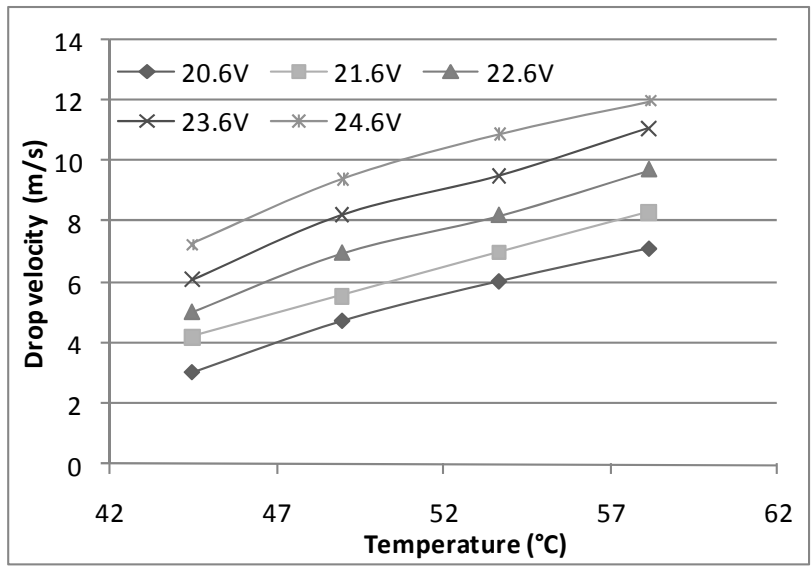

FIG.5. Temperature effect on the velocity of DC 704 silicon oil for various pulse amplitudes.
The curves drawn in Fig. (6) figure out the drop velocity decreases linearly with increasing viscosity. It emphasizes a constant slope whatever the pulse amplitude is. This phenomenon comes from the thermal dependence of viscosity. Indeed, increasing the temperature in the channel minimizes the friction forces making the liquid flow easier through the nozzle aperture.

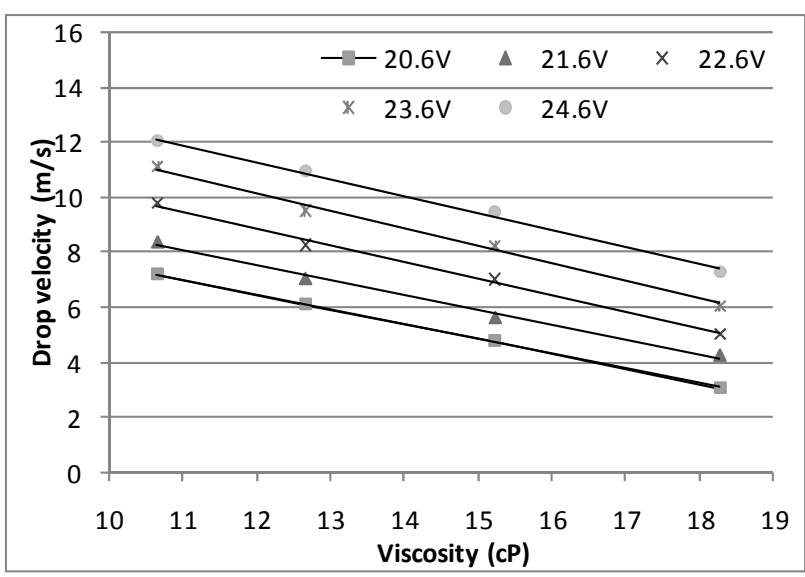

FIG. 6. Viscosity influence on the velocity of DC 704 silicon oil for various pulse amplitudes.

By combining the equations (1) and (5), we work out the final expression (7), relating the drop velocity according to both the applied voltage $U$ and viscosity $\eta$.

$\mathrm{v}=\mathrm{C}_{1} \times \mathrm{U}+\mathrm{C}_{2} \times \eta_{0} \mathrm{e}^{\mathrm{E} / \mathrm{kT}}+\mathrm{C}_{3}$

With $\mathrm{C}_{1}$ and $\mathrm{C}_{2}$ constant values depending on rheological properties of the liquid and print head characteristics. $\mathrm{C}_{3}$ is a constant independent from the applied tension and the viscosity.

Fitting (7) with the experimental results of temperature provides (8) thus modelling the behaviour of drop velocity with less than a $2 \%$ of relative error.

$\mathrm{v}=1.18 \mathrm{U}-2.4 \times 10^{-5} \mathrm{e}^{4150 /(\theta+273.15)}-10.5$

Based on (8) we can adjust the pulse amplitude to compensate for the viscosity fluctuations. In the experimentation the drop velocity is set to $6 \mathrm{~m} / \mathrm{s}$, to prevent from satellites.

Determining the coefficients $\mathrm{C}_{1}, \mathrm{C}_{2}$ and $\mathrm{C}_{3}$ we can express the pulse amplitude according to (9).

$$
U=-\frac{C_{2}}{C_{1}} \eta_{0} e^{E / k(\theta+273,15)}+\frac{v_{0}-C_{3}}{C_{1}}
$$

Applying (9) to the case of silicon oil DC704, the temperature compensation is done by (10). These variations of voltage compensation versus temperature are represented in figure 7.

$$
\mathrm{U}=-2.10^{-5} \mathrm{e}^{4150 /(\theta+273,15)}+14
$$




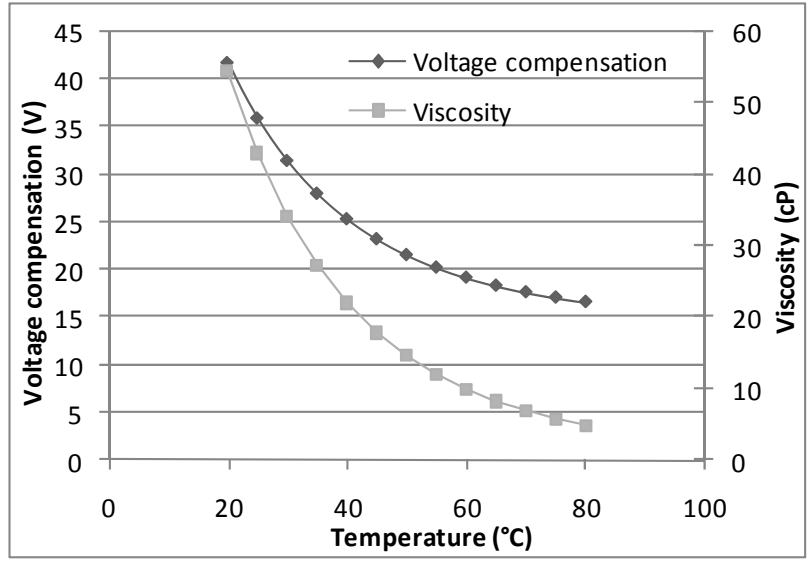

FIG.7. Pulse amplitude variation to compensate variations of temperature (drop velocity $=6 \mathrm{~m} / \mathrm{s}$ ).

To apply such regulation during the printing process, a constant access to the liquid temperature inside the print head is necessary using thermal sensors. Simultaneously the amplitude pulse has to be adjusted. In consequence, the resulting variation of drop velocity with and without temperature compensation is observed and measured (Fig. 8).

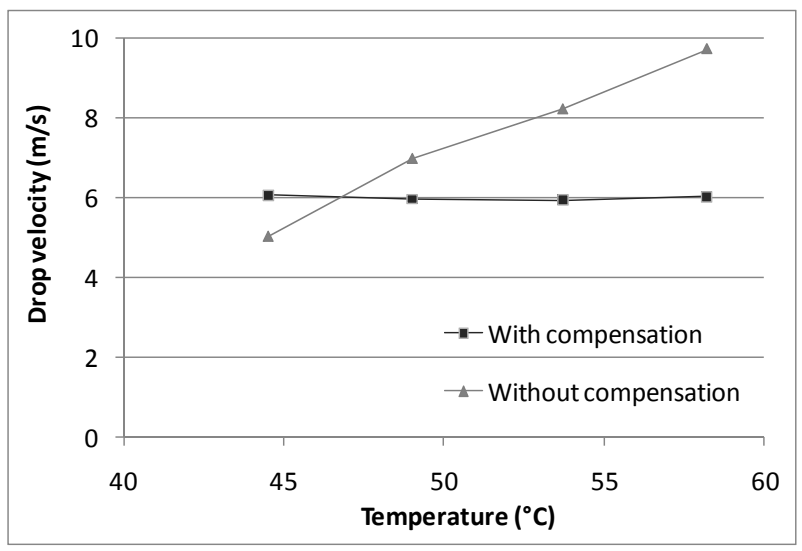

FIG.8. Velocity measurements comparison with and without temperature compensation.

The flat response of drop velocity over a $15^{\circ} \mathrm{C}$ range, compared to the $0.3 \mathrm{~m} \cdot \mathrm{s}^{-1} \cdot \mathrm{C}^{-1}$ increase without compensation, Fig. (8), demonstrates the reliability of the proposed methodology. To illustrate this result two prints, before (Fig. 9a), and after optimization (Fig. 9b) are reported. Stabilization of drop velocity reduces the satellites thus improving the print quality.

a)

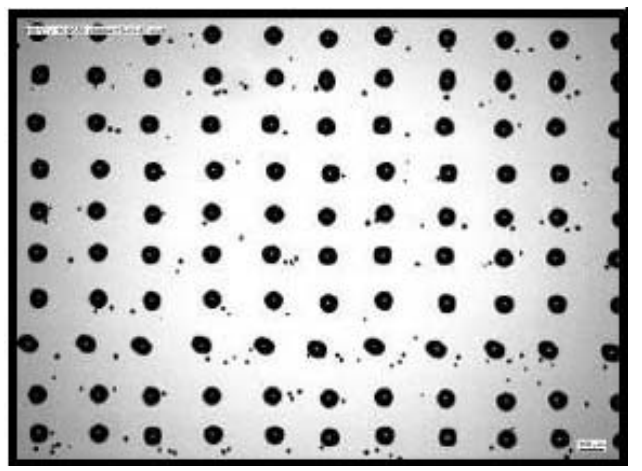

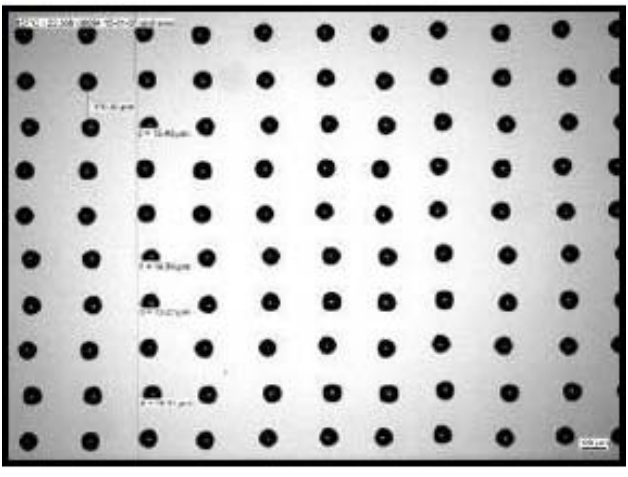

FIG.9. Print obtained without (a) and with (b) temperature compensation.

This experimental temperature compensation has been extended to a MJ style drop-on-demand single jet dispenser from Microfab ${ }^{\circledR}$ Technology. The integrated orifice and wetted surfaces are glass featured. Fluids with viscosity less than $20 \mathrm{cp}$ and surface tension in the range $20-70$ dynes/cm can be dispensed. The nozzle orifice diameter of print head is $80 \mu \mathrm{m}$. The measurements with ethylene glycol are presented in Figs (10 and 11).

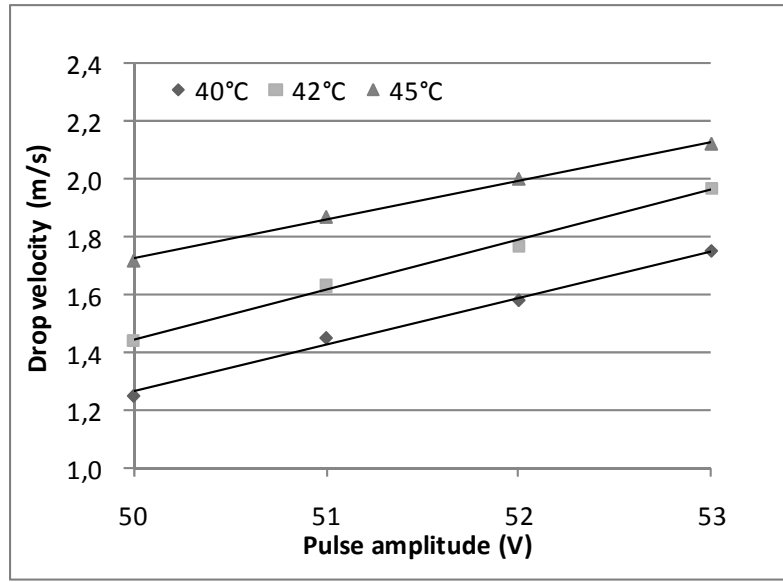

FIG.10. Velocity variation of ethylene glycol versus pulse amplitude at different temperature.

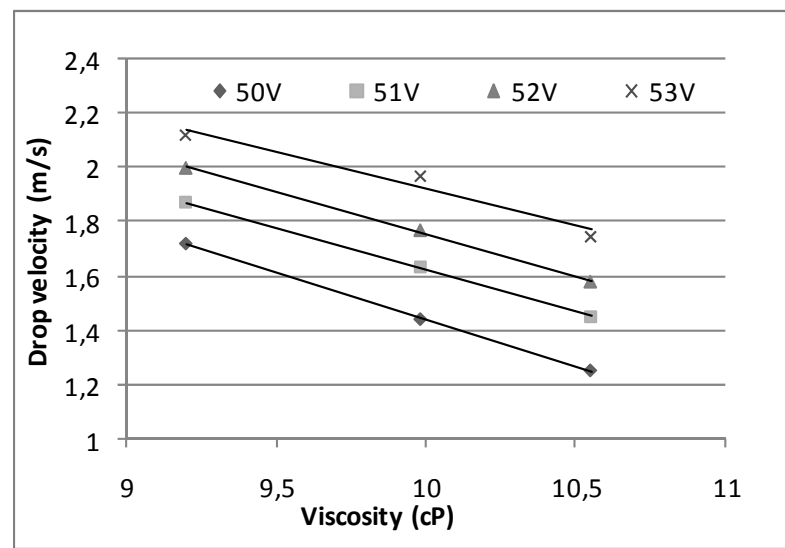

FIG.11. Velocity variation of ethylene glycol versus viscosity for various pulse amplitudes. 
Using the method of calculation described above and measuring the ethylene glycol viscosity, the expression of drop velocity as a function of pulse amplitude and temperature is:

$\mathrm{V}=0.16 \mathrm{~V}-5.6 \times 10^{-4} \mathrm{e}^{2730 /(\theta+273.15)}-3.3$

The form is almost the same like the DC704 silicon oil with a Xaar ${ }^{\circledR 760}$ print head. Only the constant values differ in (11) due to:

(i) The variation of ethylene glycol viscosity with temperature. It lower decreases than silicon oil

(ii) The geometry of the channel

(iii) The piezoelectric properties of the actuator.

The velocity regulation is performed for a constant volume of injected ink otherwise the pressure in the channel changes. In this experimentation the small capacity of manifold $(2 \mathrm{ml})$ implies a long inkjet process which dramatically modulates the velocity. As a matter of consequence the range of temperature compensation is reduced to $3^{\circ} \mathrm{C}$.

\section{CONCLUSION}

This work investigates the influence of the inkjet parameters on the drop properties to allow for a stable print. It has been first demonstrated that there is an optimal impulsion width of piezoactuator signal for each liquid. Afterward, the influence of the pulse amplitude and the liquid viscosity on the drop velocity is analytically studied. The proposed modelling is applied to perform a real time correction of temperature variation. It has been tested on silicon oil DC704 and ethylene glycol. The measurement results exhibit an almost constant velocity of the drop over a $15^{\circ} \mathrm{C}$ and $3^{\circ} \mathrm{C}$ range; respectively. These first experiments aimed the validation of the accuracy and reliability of the proposed methodology. It application is currently extended to various liquids. This second step focuses on new calibration of print head related to the ejected fluid and constant volume of manifold.

\section{REFERENCES}

[1] Wallace, D.; Hayes, D.; Shah, V.; Radulescu, D.; Cooley, P.; Wachtler, K., Nallani, A. Dallas In: Ink-Jet as a MEMS Manufacturing Tool, Proceedings of the SMTA Pan Pacific Microelectronics Symposium, Big Island of Hawaii, January 17-19, 2006.

[2] Fakhfouri, V.; Mermoud, G.; Kim, J.Y.; Martinoli, A.; Brugger, J. Drop-On-Demand Inkjet Printing of SU8. J. Micro and Nanosystems, 2009, 1, 63-67.

[3] Radulescu, D.; Trost, H.J.; Taylor, D.; Antohe, B.; Schwade, N.; Tarcha, P.; Silva, D.; Dhar S.; Evans, G. In: 3D Printing of Biological Materials for Drug Delivery and Tissue Engineering Applications. Proceedings of the IS\&T's, International Conference on Digital Fabrication Technologies, Baltimore, 2005.
[4] Liu, Y.; Cui, T.; Varahramyan, K. All polymer capacitor fabricated with inkjet printing technique. Solid-State Electronics, 2003, 47, 1543-1548.

[5] Sirringhaus, H.; Kawase, T.; Friend, R.H.; Shimoda, T.; Inbasekaran, M.; Wu, W.; Woo, E.P. Highresolution inkjet printing of all-polymer transistor circuits. Science, 2000, 2123-2126.

[6] Hue, P. Progress and Trends in Ink-jet Printing Technology. J. Imaging Science and Technology, 1998, 42, 49-62.

[7] Rayleigh, F.R.S. In: On the instability of Jets. Proceedings of the London Mathematical Society, 1878, Vol. 10, 4-13.

[8] Dong, H.; Carr, W.; Morris, J.F. An Experimental Study of Drop-on-demand Drop Formation. J. Physics of Fluids, 2006, 18.

[9] Shin, DY.; Grassia, P.; Derby, B. Oscillatory incompressible fluid flow in a tapered tube with a free surface in an inkjet printhead. Transactions of the ASME J Fluids Eng, 2005, 127, 98-109.

[10] Zapka, W.; Brünahl, J.; Wouters, O.; Mike de Roos. In: Thermometry inside Inkjet Actuators. Proceedings of the International Conference on Digital Production Printing and Industrial Applications, 2001, 392-396.

[11] Manning, H.J.; Harvey, R.A. In: Xaar Greyscale Technology. Proceedings of the International Conference on Digital Printing Technologies, Orlando, FL, USA, 19-22 October 1999, 35-39.

[12] Brünahl, J. Physics of Piezoelectric Shear Mode Inkjet Actuators. $\mathrm{PhD}$ Thesis, Royal Institute Technology, Stockholm, 2003. 